\title{
Undertone of Humour and Satire: An Analysis of Chetan Bhagat's Novel Half Girlfriend
}

\author{
Trailokya Nath Parida ${ }^{1}$ \& Itishri Sarangi ${ }^{2}$ \\ ${ }^{1}$ Lecturer in English, KISS/KIIT University. Email: trailokyanath.mitu@gmail.com \\ ${ }^{2}$ Assistant Professor, KIIT University
}

Received May 10, 2017; Revised July 24, 2017; Accepted July 30, 2017; Published August 23, 2017.

\begin{abstract}
Humour is the heart of literature that provokes laughter and provides amusement. As the main ingredient, humour intends to induce enjoyment, breaks the dullness, boredom, tiresomeness and makes the audience's nerves relaxed. George Meredith (1828-1909) in his Essay on Comedy and the Uses of Comic Spirit (1877) considers as the excellent test of the civilization of a country to be "the flourishing of comic idea and comedy" and it is of the true comedy that "it shall awaken thoughtful laughter" (Meredith 140). David Lubar an author of humorous books rightly remarks that "Humor brings pleasure, eases pain and makes the world a better place." People of all ages respond to humour and satire. "The satirist presupposes an educated readership which will easily be able to discover the implicit morality without any help other than a few ironic hints from the writer." In fact they are short in supply. This paper aims at exploring Chetan Bhagat's Half Girlfriend in terms of its tone of humour and satire. In almost all his fictions, Chetan Bhagat has captured his deep concern about the adolescence in a comic and satiric way. Mark Taiwan (1835-1910), a great humorist, entrepreneur and publisher rightly remarks that "Humour is mankind's greatest blessing." He also satirizes the so called beliefs and traditions of the society. Bhagat's present fiction Half Girlfriend sets the story of how Madhav Jha from backward Bihar is in pursuit of winning over the girl that he likes. Throughout the novel, the author has given the utmost attempt to create laughter among the readers. In fact it's true that through humorous descriptions, Bhagat has shaped many Indians to develop reading habits.
\end{abstract}

Keywords: Humour, Satire Fiction, Love, Marriage, Girlfriend

Chetan Bhagat has revolutionized the Indian writing and has stormed into the literary landscape of Indian English literature. Born on $\mathbf{2 2}^{\text {nd }}$ April 1974, Bhagat is an immortal name in the history of Indian English literature. As a columnist, author, screenwriter, television personality and motivational speaker Bhagat has acclaimed a wide range of popularity in India. Bhagat's fictional world includes Five Point Someone (2004), One Night @the Call Centre (2005), The Three Mistakes of my Life (2008), 2 States: The Story of My Marriage (2009), Revolution 2020 (2011), What Young India Wants (2012), Half Girlfriend (2014), Making India Awesome (2015) and One Indian Girl (2016).Bhagat's Half Girlfriend is a hilarious and heart touching novel among the readers.

The writer in an engineer turned investment banker made light fiction ever-present enough to adorn the selves of book stores across the country. The author needs to be praised for the humorous elements that are predominant frequently in the novel. The back cover page of Bhagat's Half Girlfriend gives the readers to take hold of quintessence quickly as the writer remarks,

(c) AesthetixMS 2016. This Open Access article is published under a Creative Commons Attribution Non-Commercial 4.0 International License (http://creativecommons.org/licenses/by-nc/4.o/), which permits non-commercial re-use, distribution, and reproduction in any medium, provided the original work is properly cited. For citation use the DOI. For commercial re-use, please contact editor@rupkatha.com. 
"Once upon a time there was a Bihari boy called Madhav. He fell in love with a girl from Delhi called Riya. Madhav didn't speak English well. Riya did. Madhav wanted a relationship. Riya didn't. Riya just wanted a friendship. Madhav didn't. Riya suggested a compromise. She agreed to be his half girlfriend" (Bhagat Half Girlfriend).

On the success story of Bhagat's Half Girlfried, Dhiviya Hariharan rightly remarks "Once again Chetan Bhagat has beat his record of writing a book that can turn out the contents of your stomach by reading just few chapters". The New York Times cited Bhagat as "the biggest selling English language novelist in India's history". Bhagat writes on the common issues and adopts a realistic approach in his fictions with comic note leading to utter success. According to Iris Murdoch (1919-1999) "Fiction must contain comedy if it attains a realistic portrayal of human life" (Hague 9). In The Language of Humour, Alison Ross (1949) remarks regarding the social aspect of comic elements and opines that perhaps the most important role of humour is to induce laughter. It reduces pain and lightens difficult situation. He defines humour as "something that makes a person laugh or smile" (1).

The novelist writes for the masses and most of times universal themes. F. Scott Fitzerald (1996-1940) estimates humour as "...the part of beauty of all literature. You discover that your longings are universal longings, that you are not isolated from anyone. You belong".The novel begins as Chetan meets Madhav Jha, the protagonist of the novel in a room in Chanakya Hotel at Patna. Madhav initiates the story about a half girlfriend as dead leaving some journals behind. In a desperate mood the frustrated hero narrates the story. Madhav Jha, chief eccentric in the novel is six feet tall, black hair with intense looking eyes. In spite of poor grasp over English Madhav manages to score a seat in the prestigious English Medium St. Stephens College, New Delhi and falls in love with a high class English speaking rich Delhi girl, Riya Somani. Unlike Madhav she is super fluent in English. Chetan makes humour to bring out the stark reality of life which catches the attention of many youngsters in the society. Bhagat is adept in using this skill frequently to get our nerves relaxed. Like many of his novels Bhagat creates characters that go for searching identity. Chetan Bhagat was bit reluctant to give time to this Bihari boy. Bhagat calls Madhav up the next morning and hears the story about the difficulties entering St. Stephens College. Madhav faces problems because of bad English and gets admission through sports quota.

The strange title itself is humorous and allures the attention of the readers at first sight. It will make you laugh many times. In Indian society normally boys and girls are not clear about their relationship status with each other. On the other hand an Indian youth may have wrong notions about girls. Most of the time the boy thinks that he is more than a friend with a girl, but the girl is still not girlfriend. Hence, a humorous title is assigned to the topic Half Girlfriend. The novelist very often tries to create laughter among the readers throughout the story. Madhav, an eager boy is trying hard convincing his favorite writer Chetan Bhagat to go through the journals of his presumed girlfriend. The writer gets a surprise look at the worst condition of multi folded journals as "many pages had holes, rats having snacked on them" (Bhagat 02).

Being a poor English speaker, Mdhav applies for admission into St. Stephen's College, New Delhi one of the famous college in India. On the interview day to get admission Madhav enquires about the location of interview room in strange English to a number of other applicants in the corridor. According to Madhav his English is not English, but 90\% of Bihari Hindi with 10\% bad English. Interestingly Madhav is turned to be an alien because of bad English when others mock at the protagonist and ask whether Madhav was there for the interview of peon. A sense of satire is smelt looking at the behavior of the guys and their comments as they mock at an innocent boy without a sense of compassion. Others present there ask “...are you interviewing for? peon?' the 
long haired boy said and laughed".(o8) An excellent sense of humour runs through the readers when Madhav faces the interview board and finds the three interviewer's grey hair which appears to him that the interviewers are not having smile since their hair turn grey.

"The three old men sat in front of me. They looked like they had not smiled since their hair had turned grey" (o9).

Madhav with lot of difficulties had practiced to say good morning to the interviewers but faces troubles because one of the interviewers mentions that he has to greet all the three interviewers present there. 'Good morning, sir, sir and sir" (o9).

In the process of interview Madhav gets ill smile and mockery from the interviewers as being a poor speaker in English. Bhagat satirizes the discouraging attitudes of the interviewers. Madhav confronts a number of obstacles during the interaction with the interviewers. He gets frustrated over the unwanted remarks by the interview board and interestingly all the three board members appear like 'English speaking monsters' to him. "Without these English-speaking monsters would eat me alive.” The Bihari boy feels like cold drops of rain on scorching summer's day when Piyush Yadav, a sports teacher interacts with him in Hindi. Madhav feels really grateful to him and thinks like a homely condition with his presence who knows Hindi.

'You know Dumraon?' I said. I could kiss his feet."(Bhagat 10)

Another hilarious situation that binds the readers comes through the answer of Madhav on the question of selecting sociology as subject that makes Madhav hurdled to answer when the interviewers ask him “...you want to take sociology. Why? Prof. Fernandez said. 'It's an easy course, need to study. Is that it?' Prof. Gupta remarked”(11). In course of events Madhav has to give trials in the basketball court and on the performance of which will enable him get admission. Waiting for the turn Madhav had to consume time before the trial and smells a good gathering near girl's trial court that could attract audience easily. The novelist satirizes the audience's attitudes for nearing girls as he remarks that girls "... sports trials always garnered an audience" (14). Opportunity comes for Madhav to have a glance of a good looking girl in the court and he feels something deep inside the heart towards the queen of the court who seeks a moment to talk to the girl. Anxiety reigns over him and he insists "to talk this girl at least once in your life" (15). Madhav observes Riya's game with keen interest and is satisfied over her playing in the court but hopes to change their point shooter. When the ball is overthrown outside the court and hits Madhav's head leading to dream the girl's vivacious beauty he takes a moment to think on it that made Riya look in surprise. Riya's surprising look compels him to think about his dress code creates light moment for the readers.

What?' she said. She surveyed me from top to bottom. I now wished I had worn better clothes .I had not changed out of my interview shirt and pants, both of which the tailor back home had stitched too close for me. I looked out of place on the basketball court. With my folder of certificates, I resembled a hero from those Hindi films of the seventiesthe one who could not find a job (16).

Another comic aspect of the novel eases the readers when Madhav does not understand the English speaking girl Riya. Madhav gives some suggestion with an intention of improvement of their game. But the whistle blows for the second half of the game. Riya is compelled to leave and says to catch later. But the innocent chap does not get it, rather gets confused whether Riya is going to catch actually and perceives just opposite. Madhav gets baffled over various situations for the bad English and faces difficulties in expressing thoughts in English and lacks proper communication skill. The purpose of the writer is to create laughter among the readers and the 
objective is fulfilled through the central character of the novel. Piyush, the sports teacher in the middle of conversation points out at him saying a 'Bihari boy'. Madhav does not realise that Piyush has mentioned with a feelings of love and affection. Rather he considers it as an offence, and changes his mind dramatically and remarks,

He could have taken offence. He had used the word 'Bihari' as if to say 'Watch, even this poor little Bihari can play', despite being a Bihari himself. However, he had helped me without knowing it, so I was grateful"(18).

At the very outset of the novel Madhav's heart goes round the tall and beautiful Riya and appreciates inside. Riya's perky voice startles most of times. Scanning over the name in the notice board to get admission in the college Madhav again comes in contact with Riya. It is hard to forget her even a single moment. Certain amount of intimacy develops between them. Both of them have conversation about their family. How Riya trusts in simplicity contrary to the family's stand. Her parents always indulge in hankering after money. With a proper tone of satire Bhagat aims at the intention of parents towards their children.

Thanks. The problem is my family. They are obsessed with money. I'm not'. "I told them I want to study music after college. They want me to marry into some rich Marwari family and live like queen. I don't want to live like a queen. That is not what I dream of (32).

Again an experience of first kiss that came from an unintentional hit of Riya's forehead with Madhav's chin is really interesting and heart touching. Instead of feeling pain Madhav feels happiness. Pain paled in front of joy the expressions by the novelist is quite amusing as,

Riya's forehead hit my chin. I bit my tongue. "Hey she said not fair'. "I held my mouth in pain. Her forehead had hurt me badly. Steel the pain paled in comparison to the joy I felt from landing my first kiss (37).

After an unintentional hit with Riya's forehead, Madhav desperately considers that kiss to be a formal or natural kiss. In spite of having no response from Riya, Madhav is happy over the experience whose heart dances with happiness. In a humorous way the novelist mentions that the happiness felt from being selected to Bihar State Team comes to second position as replaced by the happiness of the kiss to Riya and the anxious chap considered "after kissing Riya, the selection day became the second happiest"(44). A girl's presence in a boy's hostel creates Ashu, Raman and Shailesh, friends of Madhav, feel uneasy or uncomfortable. Raman asks Madhav over the presence of a girl in the boy's hostel and confirms it that he "can steel smell the perfume,' Raman said and sniffed like a cartoon character, everyone laughed" (45).

Madhav's friends ask him questions whether Madhav loves Riya or not. In response to their questions Madhav thinks them asking stupid questions.

“Did I love her? Did the earth go round the sun? Did night follow day?'(Bhagat 46)

Riya invites Madhav to her birthday party at Riya's village with family members. Madhav was bit frightened on his adjustment with a high class people. At first Madhav meets the guard at Riya's residence on 100 Aurangazeb Road and thinks about their guard and tries to understand that the high class people's layer of security that they avail. Madhav converses with the guard and smells a natural intimacy between two and considers that both of them belong to low class.

"And you are Riya madams' friend? He said. I heard the condescension in his voice. A low class can smell another low-class"(49). 
In addition to humour Bhagat satirizes the gap between high and low class people in India. People from high class enjoy their life with abundance of wealth where the common men don't get even electricity.

I entered the house, and found myself in a large living room with a shiny white marble floor. Glittering chandeliers hung from the fifteen foot high ceiling. Three sofa sets, upholstered in expensive silk were arranged in a U-shaped configuration. A teak and glass coffee table occupied the middle of the room .This is what real palace would look like if royals had actually money. I thought of my haveli with its peeling walls and cracked floors. Forget the chandeliers, we felt happy if we had less than five hours of power cuts (50).

Madhav finds Rohan, a rich boy having fancy accent, and gelled hair from London appears to be more intimate than Madhav. Madhav, a bit jealous of Rohan is baffled at the close behavior with Riya and doubts lest his boyfriend's seat be snatched by his rival. Rohan offers him drink .But to Madhav it is difficult and hardest time to digest. Rather Madhav prefers to "drink his blood" (57). Every time an impatient Madhav tries to bring his love before Riya and asks to be girlfriend. But contrary to the notion, Riya rejects the proposal and confesses to be a 'half girlfriend'. Madhav gets surprise to listen a term 'half girlfriend' and thinks about the hostel mates on this critical junction and wondered what she meant when she said 'half girlfriend'. Madhav was necessitates the "expert panel" (68). Madhav was bit confused at the failed attempt to kiss Riya and asks his expert panel for an urgent meeting.

In response to the crisis Ashu, member to the expert panel counsels and consoles him and says that the concept of 'half is not so bad and says,

"Half is not bad. Depends on how you look at it; Ashu said' .Half- empty or half -full" (69).

On the other hand Shailesh, another member to the expert panel cautions him on the idea of making a high class, fluent English speaking girl as girlfriend. Raman also supports him. Both of them make Madhav alert on the possibilities of cheating by Riya. The distinctive elements of humour and satire are quite visible through the description of the writer. The way the novelist uses the language relaxes burdened minds as,

"Hell, it's more than a warning signs,' Sailesh said. It's a fire brigade siren on maximum volume using thousand-watt amplifiers. Don't you get it, Mr. Dumraon? She is playing with you"(69).

Anyway the expert panel was also bit confused over the term 'half girlfriend'. No unanimous decision was taken by the panel. Rather in a comic way they advice Madhav to invite Riya to the boy's hostel room to change Riya and to convert the term half girlfriend to a full girlfriend and encourages him to make "Bihar proud..." (70). Riya on the other hand sticks to be just close friend, nothing more. Madhav gets breakup with Riya over the misunderstanding of girl friend. The protagonist here feels guilty over sickness of male mentality. Eventually Riya gets her marriage proposal fixed with Rohan. Riya hands over a wedding invitation to Madhav ultimately making Madhav sink in desperation. The presumed girlfriend, the core of Madhav's heart giving a weeding card was hard to digest and he is saddened as a girl giving wedding card is basically like a giant "Game Over sign flashing in a video game" (88-89).

Another hilarious situation is created when Madhav considers that girls have the rights to hurt men. Madhav finds hard to breathe and considers the biscuit pocket inside the wedding card as a consolation prize and thinks deeply that, "Rohan gets Riya Madhav gets biscuits" (90). Moreover in the story, Baghat depicts the real hostel life. Usually hostellers get difficulties in 
filling their empty stomach. Madhav doesn't throw the biscuits and decides to stick to the golden rule of hostel not to throw food. Now the relation is cut off and Madhav somewhat repeats over his mistake hankering after a rich girl who had already left but at the same time repents over the downfall of personality. He tries to stick to a Bihari boy from Dumraon and says,

"You belong to Dumraon in Bihar. That is who you are, Madhav Jha,I told myself, and that is all you will ever be and need to be" (94).

Madhav feels disgusted at the rejection of Riya and doesn't accept the offer 'HSBC' job and returns home and consoles his mother to help in school administration. The school was facing a lot of financial crisis. A true satirist is always conscious of the mistakes done by the institutions or the characters. "The true satirist is conscious of the frailty of institutions of man's devising and attempts through laughter not so much to tear them down as to inspire a remodeling" (William Thrall).

The author criticizes the condition of the village school due to inefficiency of fund which shows the real interest of the govt. on educational system of the country where fates are shaped for the interest of the nation. Madhav's mother confronts the hard consequences of the then condition of village school with various issues when she remarks as, 'every one eats my head' (95). The impression on the simple villagers by the elite class in the society is perfectly satirized in the words of the writer as, the

"over-educated idiots in the big cities. Whenever they don't understand the villagers, they call them uneducated and old fashioned."(100)

Madhav tries hard to help his mother in running the school. They get an opportunity from the local MLA to avail the lucky visit of Bill Gates, the richest person in the world and glimpse a bright chance to whitewash the pale looking walls of the school. Readers get a laughter ride for the language by the novelists as, "Because of this white guy, my school will get a white wash" (119). With bit of hesitation Madhav accepts the offer from the US Delegation to give a speech in English, one which Madhav is afraid of. Interestingly Madhav practices his speech in front his mother as,

"Good morning Mr.Bill Gates, Miss Samantha and guests. I Madhav welcoming you all to the Bihar. My school doing excellent coaching of childrens ,farmers children,poor children,small children... I couldn't think of what to say next so as I referred to various kinds of children .I continued,(...)boy children, girl children, and many, many children"(125). Madhav faces a lot of difficulties in speaking the language and was compelled to think that "he has murdered English" all his life (134).

Miraculously Madhav discovers Riya Somani in a restaurant at Patna and avails the opportunity to look from her back and confirms none, but to be Riya. Unfortunately Riya cannot notice Madhav and leaves. But Madhav is afraid of following Riya immediately lest she "might run away" (137). Incidentally Riya meets and offers a friendship to Madhav. Madhav is reluctant to go for just-friend deal again .But Riya distances from physical attachment. Riya is agreed to help in learning English speech to be delivered in the presence of Bill Gates. Everything goes well accordingly. But to utter surprise, Riya disappears from that occasion leaving a letter to Madhav that she is caught with lung cancer and death is inevitable.

The author attacks the attitude of Madhav's mother who doesn't accept Riya, a divorcee as daughter-in-law. She is unresponsive to the happiness of her son. Now Madhav is in New York and is informed about an Indian singer's performance at the night bar. To the heart breaking 
surprise of the readers Madhav discovers Riya Somani there. To our utter delight two hearts are united with deep and heart breaking emotion. The novel comes to an end with a rosy picture of their conjugal life at Dumraon. Riya's presence made Madhav's life colorful and they now lead happy life with their son. "Comedy is the art of making people laugh without making them puke" (Steve Martin)

Humour is the important aspect of everyday life. The point is that this tool can be used to face the hardest times in our life and at the same time we can appreciate some of the most outstanding times. With a pinch of humour we can change our life to a different direction however we are over shadowed by the shadows of sadness. In fact it is true that without humour hard times seem harder to handle. Jane Austen in her Pride and Prejudice, Mark Taiwan in his The Adventures of Huckelberry Finn, Harper Lee in her novel To kill a Mockingbird and Charles Dicken in his Great expectations have wide impact and lasting impressions on the readers. Throughout the novel Chetan Bhagat has been successful in using tremendous skill of humour and satire. Indianness in his themes makes his novels more interesting who invented the genre of contemporary Indian writing. Before this average Indian readers were fed a diet of Sydney Sheldon, Jeffrey Archer, and John Grisham etc. all of whom wrote about American system. Indian authors Sobha De, R.K.Narayan, Amitav Ghosh and others choice of setting were in a long bygone era or just too outside the scope of common man's dreams. But Chetan Bhagat's novels are directed to the common man's dreams. He beautifully presents a common tale of common man of India. In fact he takes up issues which reverberate with the masses. The novel is entertaining. Bhagat ensures reader's engagement for the most part of the book and there is simple humour peppered throughout the story with ample entertainment and that holds mass appeals. After all it's a charming love story that provides a lot of humour and satire to the readers. By means of good humour we can have opportunity to step back and see what is most important in life. To cut the long story short it is true that Chetan Bhagat has shaped the many Indian's reading habits creating light moments for readers. Because of the funny elements his novels are not for the elite and limited readership but for the masses.

\section{References}

Bhagat, Chetan. 2014. Half Girlfriend. Rupa \& Co, New Delhi.

Abrams, M.H. 2016. Geoffrey Galt Harpham . A Glossary of Literary Terms. Cengage Learning India Pvt. Ltd, New Delhi.

Meredith, George. And Maura C. Ives. 1988. George Meredith's Essay on Comedy and Other New Quartely Magazine Publications: A Critical Edition. Lewisburg: Bucknell UP.

Ross, Alison. 1998. The language of Humour. Routledge, Abingdon.

Thrall, William, Addison, Hibbard and C. Hugh Holman. Eds. 196o. A Handbook to Literature. New York: Odyssey Press.

\section{Web Sources:}

www.goodreads.com /book/show/22874559-half-girlfriend,Accessed $25^{\text {th }}$ Nov. 2016.

www.sarthakahuja.com/2014/11/summary-review-of-half - girlfriend-chetan-bhagat.html. Accessed 14 Nov. 2016. 
www . timesofindia.indiatimes.com>chetan...Accessed 23 Nov. 2016.

www.decanchronicle.com>chetan bhagat, Accessed 26. Nov 2016.

https://literary devices.net, Accessed 10 Jan. 2017.

https://en.m.wikipedia.org.Accessed 18 Apr. 2017

https://www.brainyquote.com/quotes/m/marktwainı637o.html Accessed 6 Aug 2017 